Thompson (toim.), Interaction and grammar s. 52-133. Cambridge: Cambridge University Press.

- 2007. Sequence organization in interaction. A primer in conversation analysis. Volume 1. Cambridge: Cambridge University Press.

Stevanovic, Melisa - Peräkylä, Anssi 2012: Deontic authority in interaction. The rights to announce, propose, and decide. - Research on Language and Social Interaction 45 s. 297-321.

Stivers, TAnya 2005: Modified repeats. One method for asserting primary rights from second position. - Research on Language and Social Interaction $38 \mathrm{~s}$. 131-158.

Stivers, Tanya - Mondada, Lorenza

- Stennsig, Jakob 2011: Knowledge, morality and affiliation in social interaction. - Tanya Stivers, Lorenza Mondada \& Jakob Steensig (toim.), The morality of knowledge in conversation s. 3-26. Cambridge: Cambridge University Press.

TAinio, LiIs A 1996: Kannanotoista arkikeskustelussa. - Auli Hakulinen (toim.), Suomalaisen keskustelun keinoja II s. 81-103. Kieli 10. Helsingin yliopiston suomen kielen laitos.

— 1997: Preferenssijäsennys. - Liisa Tainio (toim.), Keskustelunanalyysin perusteet $\mathrm{s}$. 93-110. Tampere: Vastapaino.

Tomasello, Michael 2008. Origins of human communications. Cambridge: MIT Press.

\title{
Kauan eläköön suomi!
}

Lari Kotilainen: Kielen elämä. Suomen kieli eilisestä huomiseen. Helsinki: Siltala 2016. 239 s. ISBN 978-952-234-367-3.

Lari Kotilainen tunnetaan suomen kielen tutkijana, akateemisena opettajana ja kielen sekatyöläisenä, joka kirjoittaa blogia nimimerkillä Suomensuojelija (ks. http://www.suomensuojelija.fi). Aiemmin hän on julkaissut samannimisen teoksen, jonka alaotsikkona on Ohjekirja kielen pelastamiseen (ks. Kotilainen 2009). Lukijan ei siis uutta teosta avatessaan tarvitse arvailla, mikä on Kotilaisen suhde ja asenne suomen kieleen. Hän tekee työtä sen hyväksi sekä tosissaan että leikillisesti. Tämän arvostelun otsikko on lainattu teoksen ensimmäiseltä luvulta.

Kielen elämä on rennolla otteella kirjoitettu suomen kielen elämäkerta. Se lähtee liikkeelle tuhansien vuosien takaa kantauralista ja päätyy kurkistamaan nykyhetkestä muutaman kymmenen vuoden päässä odottavaan tulevaisuuteen. Aikamatka ei kuitenkaan jakaudu tasaisesti eri kehityskausien osalle. Kaikki esikristilliset vuosituhannet on kuitattu 16 sivulla, ja suunnilleen samanmittainen on suomen kielen esikirjallisten vaiheiden osuus ajanlaskun alusta reformaation kynnykselle. Agricolalle ja suomen kirjakielen synnylle on omistettu parikymmentä sivua. Se on hieman enemmän kuin on saanut osakseen koko Ruotsin ajan loppupuoli Agricolasta eteenpäin. Sitten repeää: 180o-luvun kehitystä käsittelevä osuus on peräti 67 sivun mittainen. 1900-lukuun keskittyvä "Suomi voimainsa tunnossa" on taas yllättävän lyhyt, niukat 17 sivua. Kirjan neljässä viimeisessä luvussa Kotilainen tutkailee 200o-luvun nykyisyyttä ja tulevaisuutta yhteensä 59 sivun verran. Lo- 
pussa on joukko "Larisdamuksen" ennustuksia siitä, mitä suomen kielelle jatkossa tapahtuu tai ei tapahdu.

\section{Reippaasti subjektiivinen}

Populaarin tietokirjan kirjoittaminen on kurinalaiselle tutkijalle mukavaa vaihtelua. Käsiteltävät asiat ja painotukset saa valita oman kiinnostuksensa mukaan, eikä sen enempää kirjoittajan kuin lukijankaan tarvitse painiskella yksityiskohtaisten lähdeviitteiden ja kattavuusongelmien kanssa. Riittää, että kirjan sisältö on suurin piirtein ajan tasalla ja vastaa niihin odotuksiin, joita lukijan mielessä herää kirjan otsikkoa tavaillessa. Tämä tarkoittaa sitä, että enimmäkseen on käsiteltävä niitä samoja asioita, joita muutkin ovat käsitelleet vastaavan tyyppisissä yleisesityksissä.

Kotilainen on useissa kohdin maininnut, kenen tutkimuksista hänen käyttämänsä tiedot ovat peräisin, mutta ei mitenkään systemaattisesti. Teoksen lopussa on luvuittain jaoteltu kirjallisuusluettelo, josta saa lisää osviittaa. Huomattavan suuri osa lähteistäkin on yleisesityksen luonteisia.

Teoksessa ei ole omia uusia tutkimustuloksia, eikä siinä kuulukaan olla, kun kysymys on yleistajuisesta tietokirjasta. Kotilainen tekee lukijalleen hyvin selväksi, ettei hän ole itse keksinyt eikä tutkinut kaikkea sitä, mitä teos sisältää, vaan sen ainekset on koottu laajan tiedeyhteisön pitkien aikojen kuluessa tuottamasta tietopääomasta. Johdantoluvussa Kotilainen lupaa lukijalle runsaasti yllätyksiä, mutta niiden määrä riippuu ratkaisevasti siitä, mitä lukija tietää ennestään ja miten aktiivisesti hän on seurannut suomen ja sen sukukielten tutkimuksen edistymistä. Kirjassa ei erikseen ole määritelty sitä, millaiselle lukijakunnalle se on suunnattu. Teos on omistettu kirjastoille, joiden tekemälle loistavalle sivistystyölle Kotilainen antaa tunnustusta teoksen loppusanoissa.

Kotilainen ei piiloudu passiivien taakse. Hän kirjoittaa mutkattomasti minä-muo- dossa ja ottaa suoran kontaktin lukijaan: "Mitäs siihen sanotte!" (s. 9) ja "Lue eteenpäin, niin tiedät" (s. 11). Joissakin kohdin, esimerkiksi astevaihtelun esittelyssä, "Odottakaahan vain!" -tyyppiset (s. 41) innostavat huudahdukset tuntuvat hieman setämäisiltä keinoilta pitää yllä lukijan mahdollisesti hiipuvaa kiinnostusta. Tyyli vaihtelee neutraalista asiaproosasta jutusteluun, ja joukkoon mahtuu lieviä voimasanojakin (s. 10): "Nyt tarvittiin kirjoitusta, ja mieluiten aika pirun nopeasti."

\section{Palapelin ongelmia}

Monien eri-ikäisten lähteiden käyttämisestä saattaa seurata, etteivät mukaan poimitut palaset sovi saumattomasti yhteen. Kantauralin uusissa rekonstruktioissa on $i$-loppuisia sanoja, jollaisista Kotilainen mainitsee esimerkkeinä sivulla 18 sanat meti 'mesi' ja mekshi 'mehiläinen'. Aiemmassa äännehistoriassa tämäntyyppiset muodot on rekonstruoitu e-loppuisiksi. Sivulla 24 Kotilainen esittelee kantasuomalaista $t i-s i$-muutosta ja sen kontekstia todeten, että muutoksen on laukaissut sananloppuisen $e$ :n muttuminen $i$ :ksi. Juuri edellä mainittu mesi äännevaihteluineen olisi hyvä esimerkki tästä. Tarkka lukija saattaa herätä kysymään, mistä se sananloppuinen e nyt ilmestyi, kun lopussa on ollut $i$ kantauralista lähtien.

Poimintoihin saattaa myös jäädä aukkoja ja epätarkkuuksia. Kantauralin esimerkkisanoissa käytetyt äännemerkinnät (s. 26) eivät aukene lukijalle ilman selityksiä, jotka on hoksattava hakea omatoimisesti tekstissä mainitusta verkkodokumentista. Kantauralin taivutusmuotojen esittelyssä jää epäselväksi, onko duaalimuoto *tolimajn ajateltu preesensin vai imperfektin muodoksi. Toisaalta se ja pari muutakin kantauralin muotoa on rinnastettu suomen imperfektimuotoihin tulin, tulimme, mutta merkitykseksi on annettu 'me kaksi tulemme.' Lehtisen kirjassa Kielen vuosituhannet (2007: 69) on preesensinä ja kysy- 
mysmerkillä varustettuna melkein sama muoto, mutta sen toisessa tavussa on takainen $\dot{b}$ ei normaali etuvokaali. Vokaalin laatu on olennainen asia sekä morfologisen analyysin että vokaaliharmonian kannalta.

Varsinkin historiallisten lähteiden käyttäjille tuttu ongelma on se, että henkilöiden nimet kirjoitetaan eri yhteyksissä eri tavalla. Oliko ensimmäinen suomen kielen professori Matthias Alexander (s. 19) vai Matias Aleksanteri (s. 152) Castrén? Tiedekirjoissa näitä herätään usein yhtenäistämään vasta siinä vaiheessa, kun laaditaan henkilöhakemistoa, mutta kun yleistajuisissa opuksissa ei sellaisia yleensä ole, asia ei tule tekijöille konkreettisesti vastaan.

\section{Tekevälle sattuu}

Selviä virheitä teoksessa on vain vähän. Yksi lipsahdus on sivulla 39, jossa astevaihtelu kuvataan sanan lopussa sijaitsevien konsonanttien muuttumiseksi. Esimerkkisanojen sarja kuitenkin pelastaa tilanteen. Sivulla 72 todetaan, että vuoden 1642 Bibliassa osattiin jo kirjoittaa pitkä vokaali kahdella vokaalimerkillä sanan alussa, kun tarkoitetaan ensi tavua. Sivulla 120 kerrotaan E. N. Setälän osin kopioimalla syntyneestä kieliopista, kun tarkoitetaan ilmeisesti legendaarista lauseoppia.

Kantaurali-termiä käytetään sekä kantakielen että sen puhujien nimityksenä (s. 26). Ljalovon kulttuuri on muuttunut Ljavolon kulttuuriksi (s. 18). Kielenhuollon entiseksi nimitykseksi on ilmoitettu oikeinkirjoitus, kun tarkoitetaan ilmeisesti oikeakielisyyttä (s. 159).

\section{Mitä puuttuu?}

Yleistajuisessa esityksessä on pakko vetää mutkia suoraksi reippaalla kädellä, kun käsiteltävä kehityshistoria on useiden tuhansien vuosien mittainen. Kielen muuttumista on kuvattu enimmäkseen sanaston uudennoksia esittelemällä. Äänneja muoto-opista on valikoitu esimerkki- tapauksia, mutta kokonaisia järjestelmiä tai osajärjestelmiä on turha hakea. Kantauralin sijamuotojen määräksi mainitaan seitsemän (s. 25), mutta ei kerrota, mitkä ne olivat, kuten ei sitäkään, että sijajärjestelmän historiaa on viime vuosina tutkinut innovatiivisesti varsinkin Jussi Ylikoski (2016). Tilanne elää koko ajan.

Agricolan aikaansaannosten arvioinnissa olisi voinut kertoa myös uusimmasta tutkimuksesta, joka koskee Agricolan painettuja teoksia vanhempia käsikirjoituksia. Näitä on äskettäin julkaistu verkossa Suomalaisen Kirjallisuuden Seuran Codices Fennici -hankkeen sivuilla (ks. https:// www.codicesfennici.fi). Esiagricolalaisten käsikirjoitusten avulla voi konkreettisesti osoittaa, että Agricolan teoksiin sisältyy myös aiemmin suomennettuja osia. Tämä olisi täydentänyt lukua, joka käsittelee Agricolan sankarimyyttiä (s. 64-67).

Virkakielen ja virkamiehistön rooli jää kirjakielen historiaa pohdittaessa takaalalle, vaikka julkisuuden kielen kannalta se oli äärimmäisen tärkeä. Jo Ruotsin ajan suomenkieliset asiakirjat ja erilaiset säädökset tekivät kansalle tutuksi sekä virallisen esitystavan että suuren määrän uutta sanastoa. Nykysuomen kauden alkuvaiheessa olennainen edistysaskel oli se, kun virkamiehiksi ja muihin julkisiin tehtäviin alkoi tulla väkeä, joka oli saanut koulusivistyksensä suomen kielellä. Venäjän kielen asemaa 180o-luvulla käsiteltäessä tahtoo aina unohtua armeija ja sotilaskoulutus. Haminan kadettikoulussa koulutettiin suomalaisia upseereja Venäjän armeijaan ja opetuskieli oli venäjä.

Paikoin asiat on selitetty niin suurpiirteisesti, että ne voi ymmärtää monella tavalla. Esimerkiksi sivulla 47 kerrotaan, että ensimmäisiä lyhyitä suomeksi kirjoitettuja tekstejä alkoi ilmaantua 140o-luvulla. Tarkoittaako tämä niitä katekeettisia tekstejä, joita jo keskiajalla piti lukea kansankielellä jumalanpalveluksissa mutta joista ei ole säilynyt yhtään dokumenttia? Vai viittaako kohta niihin kahteen suomen- 
kieliseen lauseeseen, jotka ovat säilyneet 140o-luvun puolivälin tienoilta erään saksalaisen pappismiehen matkakertomuksessa (s. 54)? Vai jotakin muuta?

Nimistön muuttumista ei käsitellä ollenkaan. Ainoastaan ulkomaisen paikannimistön suomalaistamispyrkimykset tulevat puheeksi $1800-$ luvun kielenuudistuksen yhteydessä. 180o-luvun esittelyyn olisi saanut lisää särmää käyttämällä lähteenä esimerkiksi Sulkusen (2004) kirjoittamaa Suomalaisen Kirjallisuuden Seuran historiikkia. Siinä saavat huutia suurmiehet Lönnrotista alkaen.

Taustakirjallisuuden kohdalla jää ihmettelemään, miksi luettelosta puuttuvat Pirjo Hiidenmaan Suomen kieli - who cares? (2003) ja Kotimaisten kielten tutkimuskeskuksen Suomen kielen tulevaisuus: Kielipoliittinen toimintaohjelma (Hakulinen, Kankaanpää, Kanner, Koskenniemi, Laitinen, Maamies \& Nuolijärvi 2009). Niissä on paljon samaa asiaa kuin Kotilaisen teoksessa mutta yleensä eksaktimmin esitettynä. Alan oppikirjaa kaipaavalle olisi voinut antaa vinkiksi Turussa toimitetun kolmiosaisen artikkelikokoelman Suomen kieli: Opiskelijan tietokirja (2011-2014).

Kuvia Kotilaisen teoksessa on niukasti, vaikka juuri niiden avulla voisi helposti havainnollistaa tai korvata pitkiä selityksiä. Esimerkiksi sukukielten puhuma-alueet tai kielikunnan muinaiset ydinalueet olisi voinut esitellä perinteiseen tapaan kartoilla. Jokunen murrekarttakin olisi ollut paikallaan murre-erojen esittelyn yhteydessä.

\section{Enimmäkseen näyttää hyvältä}

Teoksessa käytetyt kirjaintyypit ja niiden tekijät on esitelty nimiön kääntöpuolella. Leipäteksti on mukavan selvää ja miellyttävää. Siitä voidaan kuitenkin kiistellä, onko kovin monen fontin käyttäminen tarpeellista. Etenkin 1800-luvun uudissanalistat, jotka on omalla kirjaintyypillään merkitty sivujen alanurkkiin, tekevät sivuista sekavan näköiset.
Kannen tekijäksi on ilmoitettu vain Aleksi Salokannel siitä huolimatta, että kansikuvasta suurin osa on tarkkaa kopiota Albert Edelfeltin tunnetusta Agricolan muotokuvasta. Kirjoituspulpetin paikalle on tosin vaihdettu miksauspöytä ja Biblian paikalle levysoitin. Esimerkkilauseet on korvattu tavanomaisilla kansiteksteillä. Tekijänoikeuksia ei toki ole loukattu, koska Edelfeltin vanha piirros on jo niiden ulottumattomissa, mutta jotakuta saattaisi aivan oikeasti kiinnostaa se, kuka alkuperäisen kuvan on tehnyt.

\section{Mieltä lämmittäviä havaintoja ja yksityiskohtia}

Teoksessa on monia yksityiskohtia, jotka tuovat esiin kielen elämän inhimilliset puolet. Sivulla 30 kerrotaan, kuinka akkalansaamen kolmesta viimeisestä puhujasta kaksi kuoli moottorikelkkavarkaan luoteihin. Erityistä huomiota saa osakseen $\ddot{o}$-vokaali, jonka kunniaksi komin kielen puhujat ovat pystyttäneet peräti patsaan (s. 45). Myös suomen ö:n ilmaisuvoimaa havainnollistetaan paljonpuhuvin esimerkkisanoin.

Varttuneelle fennistilukijalle parasta antia ovat pienet henkilökohtaiset huomiot ja muistelmat. Kotilainen kertoo esimerkiksi innostavasta opettajastaan Silva Kiurusta ja venäläisestä tuttavastaan, joka päätti ryhtyä opiskelemaan suomen kieltä (s. 49-50). Tämä oli muiden paikallisten nuorten kanssa joutunut arvuuttelemaan, ketä Viipurin kirjaston aulassa seisonut kuvapatsas esitti, ja kun selvisi, että se ei ollutkaan Väinämöinen vaan Agricola, hän kävi kirjastossa anomassa Agricolalta tukea opintosuunnitelmilleen.

Teoksen loppupuolella on paljon sellaista asiaa, joka perustuu Kotilaisen omiin tutkimuksiin ja kokemuksiin. Uudissanalistoja voi toki lukea myös Kotimaisten kielten keskuksen verkkosivuilta, mutta Kotilainen esittää samat asiat paljon hauskemmin. Hän kertoo mieltymyk- 
sistään ja tuntemuksistaan, kommentoi ja tekee päätelmiä. Parasta kaikessa on kuitenkin Kotilaisen vilpitön kiinnostus ja intomielinen asenne, jolla hän kertoo suomen kielen menestystarinaa. Se on aivan muuta kuin se kyyninen vähättely, jota fennisti on joutunut turhan usein kuulemaan jopa omiensa joukossa. Suomen kieli on hieno kieli! Toivottavasti sen ystävien joukko kasvaa entisestään Lari Kotilaisen teoksen myötä.

\section{KAISA HÄKKINEN etunimi.sukunimi@utu.fi}

\section{Lähteet}

Codices Fennici. Suomen keskiajan ja 150o-luvun käsikirjoitukset. www.codicesfennici. fi (11.7.2017).

Hakulinen, Auli - Kalliokoski, Jyrki

- KankaAnpä̈̈, Salli - Kanner, Antti - Koskenniemi, Kimmo -

Laitinen, Lea - MaAmies, Sari

- Nuolijärvi, Pirkko 2009: Suomen kielen tulevaisuus. Kielipoliittinen toimintaohjelma. Helsinki: Kotimaisten kielten tutkimuskeskus.
HitdenmaA, Pirjo 2003: Suomen kieli who cares? Helsinki: Otava.

Kotilainen, Lari 2009: Suomensuojelija. Ohjekirja kielen pelastamiseen. Helsinki: WSOY.

Lehtinen, TAPANi 2007: Kielen vuosituhannet. Suomen kielen kehitys kantauralista varhaissuomeen. Tietolipas 215. Helsinki: Suomalaisen Kirjallisuuden Seura.

Sulkunen, Irma 2004: Suomalaisen Kirjallisuuden Seura 1831-1892. Suomalaisen Kirjallisuuden Seuran toimituksia 952. Helsinki: Suomalaisen Kirjallisuuden Seura.

Suomen kieli. Opiskelijan tietokirja 1-3. Turun yliopiston suomen ja sen sukukielten oppiaineen julkaisuja 1. Turun yliopiston suomen kielen ja suomalais-ugrilaisen kielentutkimuksen julkaisuja 1, 5 . Päätoimittaja Kaisa Häkkinen. Turku 2011-2014.

YLIKOSKI, Jussi 2016: The origins of the western Uralic s-cases revisited. Historiographical, funtional-typological and Samoyedic perspectives. - FinnischUgrische Forschungen 63 s. 6-73.

\section{Politiikan kielen analyysia yleistajuisesti}

\section{Vesa Heikkinen \& Tapio Pajunen: Kansalaistaito. Miten politiikkaa voi ymmärtää, jos sitä voi ymmärtää? Helsin- ki: Teos 2016. 352 s. ISBN 978-951-851-700-2.}

Kieli on vallan väline, ja politiikka on kielen käyttöä. Siten politiikan ja kielen suhteen ymmärtämistä ja taitoa eritellä poliittista kieltä voidaan pitää kansalaistaitona, johon on perinteisesti luettu yhteiskunnallisia toimintavalmiuksia ja taitoa ajatella kriittisesti (ks. esim. Belt \& Tuusvuori 2017). Vesa Heikkisen ja Tapio Pa- jusen teos Kansalaistaito pureutuu politiikan kieleen ja teksteihin. Tekijät ovat paitsi alan asiantuntijoita myös kokeneita toimittajia. Heikkinen on tutkinut pitkään kielen ja vallankäytön suhdetta, ja Pajunen on politiikan toimittaja. Yhdessä he ovat tehneet Yleisradiossa ohjelmia kielestä ja politiikasta.

Kansalaistaito pyrkii tarjoamaan työkaluja politiikan tekstien tulkitsemiseen sekä tekemään kielen ja politiikan suhdetta ymmärrettäväksi ja näin kehittämään politiikan "sisälukutaitoa". Teos 